\title{
Softening the hierarchy: the role of student agency in building learning organisations
}

Stephanie Hill

University of Cambridge, Cambridge \& Passmores Co-operative Learning Community, Harlow

\begin{abstract}
Purpose - This paper explores the role of student agency in building learning organisations based on a case study of a student learning community (SLC) model that incorporates learning-centred dialogue between students and teachers.

Design/methodology/approach - The case study adopted a multi-phase design involving multiple perspectives. Data was collected using questionnaires and semi-structured interviews following student and teacher involvement in two classroom events and subsequent dialogic encounters.

Findings - Key insights emerged demonstrating the value of the SLC model in creating conditions that support learning organisations by enabling pedagogical spaces where students and teachers learn together, as well as the need for this model to encompass marginal voices and negotiate alternative approaches to accountability.
\end{abstract}

Research limitations/implications - This small-scale case study was based on a purposive sample of 10 teachers and 14 students from a single school setting in England. Therefore there are limitations in generalising results to other contexts. Furthermore, the use of selfreport measures to examine this case limits analysis of the case study conditions.

Practical implications - The investigation provides insight into the implementation of this model through a consideration of teacher-student relationships, guidelines for dialogic encounters, training in student-led lessons and observations, as well as factors concerning the inclusivity and authenticity of this approach.

Originality/value: Growing interest in student agency emphasises the importance of further investigation into initiatives aiming to develop meaningful student involvement. This paper provides new perspectives on the insights generated by the SLC model in order to support the development of student agency models in other schools.

Keywords - student agency, learning communities, learning organisations, dialogue, professional learning

Paper Type - Research paper 


\section{Introduction}

There is growing evidence that students can be powerful agents and catalysts for change in school improvement (Beltramo, 2018; Fullan, 2013; Fielding, 2011; Mullis, 2011; Roberts \& Nash, 2009; Cook-Sather, 2002). Recent literature suggests that when schools function as learning organisations, students will succeed (Senge et al., 2012; Giles \& Hargreaves, 2006). Despite the criticism of student voice initiatives as tokenistic additions to school improvement plans or fleeting reactions to school inspections (Bahou, 2012; Black, 2011; Lundy, 2007), there is merit in expanding on this field.

This paper presents a recent case study of how a school worked against the tide of centralisation and direct instruction to create a collaborative student learning community (SLC). A SLC is defined here as collaboration between teachers and students where students have genuine agency and time to reflect upon their learning in lessons, with the purpose of making this more meaningful and engaging.

School improvement measures are problematic in determining the value of student agency models (Black, 2011). Researchers usually draw on quantitative attainment data (Stoll \& Fink, 1996; Hargreaves, 2010) and performativity measures in the form of external targets and indicators (Ball, 2003; Fielding, 2001a). This paper explores the possible impact of the student agency model by investigating how the SLC approach contributes to the conditions required for learning organisations (Senge et al., 2012; Reynolds, Murrill and Whitt, 2006).

\section{Background Literature}

\section{Theorising the learning organisation}

Although definitions of what constitutes a learning organisation (LO) are diverse (Thomas \& Allen, 2006), most agree that a LO creates conditions where all members learn together so that they thrive and can continuously transform the organisation (Reynolds et al., 2006; Sun, 2003). It is a fitting framework for interrogating arguments surrounding the role of students in organisational change (Senge et al., 2012), asserting the need to look beneath the architectural structure of an organisation (which often leads to a disproportionate focus on the role of leadership) to the learning processes that occur at the individual, group and finally the system level (Moloi, 2010). As Garvin, Edmondson and Gino explain, in a business environment organisations have historically "overemphasized the forest and paid little attention to the trees" $(2008$, p. 2 ) and it is only in recognising the contributions that all stakeholders make to organisations that they will succeed. In the same sense, schools will only be equipped to meet the challenges of an increasingly volatile education system if they understand how to adapt themselves to change and how best to learn how to implement new ideas (Sun, 2003, p. 154) by developing the agency of all stakeholders, particularly young people. LOs have been criticised for limiting organisational hierarchy by ignoring the role of the leader (Pedler \& Burgoyne, 2017), and failing to acknowledge the tensions and contradictions of learning in complex contexts (Vince, 2017). However, Pedler \& Burgoyne also note that LOs provide a way in which the traditional barriers to the "upward flow of information" (2017, p. 120) can be overcome and used to improve the organisation as a whole. Indeed, it is the way that participants in an LO develop and interact which is essential to its success (Senge, 2006). Within educational scholarship this is clearly evident in the 
development of theory around professional learning communities (Stoll \& Fink, 1996, Fielding, 2001b) and in particular, Hargreaves and Fullan's (2012) notion of professional capital, which sees the collective and individual mechanisms of human, social and decisional capital as the key drivers for improving schools.

Recently, Hargreaves and O'Connor (2018) have gone further, publishing ten tenets of Collaborative Professionalism in the form of indicators which aim to guide organisations in designing ways in which teachers and students can work together. They claim that "in the deepest forms of collaborative professionalism, students are actively engaged with their teachers in constructing change together" $(2018, p$. 7). This reinforces the central role that students play in developing a learning organisation. Indeed, it also leads to a much deeper consideration: could a model that supports student agency become the key driver for creating the conditions required to build a learning organisation?

This paper draws on the broad views of learning processes introduced in the previous paragraphs and adds ideas from Argyris $(1977,1991)$, whose work is widely acclaimed in this field, and Moloi (2010), who applies learning organisation theory to an education context. These are captured in the Senge's (2006) five disciplines of a learning organisation: (1) personal mastery, or coming to understand personal vision and capacities; (2) shared vision, or developing a shared purpose that drives action (3) mental models, or becoming aware of assumptions and perceptions and their impact on individual and collective thinking; (4) team learning, or working together and experiencing the other in order to achieve common goals; and (5) systems thinking, or understanding one's role in a community (how each person's actions affect the organisation) and viewing the organisation from a 'big picture' perspective. These disciplines are supported by the mechanisms of dialogue and reflection (Senge et al., 2012, pp. 7-8) and most importantly, they offer effective ways for organisations to build a system of learning that requires students to be at the heart of this organisational change.

\section{Theorising the Student Learning Community}

Recent scholarship on student involvement in school improvement is diverse: from student voice initiatives such as student councils, that largely focus on features of the school yard, the food in the canteen or changes to the school uniforms, to case studies into student involvement projects where students are central to key changes in school curriculum, policy or practice (Bahou, 2012; Czerniawski \& Kidd, 2011; Roberts \& Nash, 2009).

Rudduck and McIntyre's (2007) seminal research, carried out in the Teaching and Learning Research Programme, found that pupil consultation about what was happening in classrooms not only led to improvement in teaching practice but also enabled students to see themselves as active contributors to this. Moreover, in her study on consulting pupils within the classroom, Morgan (2011) concluded that there are benefits for both teachers and students in consulting the classes they teach, but success is contingent upon key contextual conditions that support and encourage this practice. In focusing on a student voice initiative without external support, she also acknowledged that less is known about how students contribute to school improvement without external mandates or outside agencies.

The study in this paper sought to build upon scholarship that explores sustained student involvement (Mullis, 2011; Fielding, 2011; Rudduck \& Fielding, 2006), student participation models (Hart, 1992; Shier, 2001) and partnership frameworks (Fielding, 2011) in order to 
seek further understanding of the sustainability and impact of student input within a school setting.

For this study, the term 'student agency' was used instead of 'student voice'. The term emerged from a more rigorous investigation of the development of student involvement in previous work (Hill, 2015). It seeks to acknowledge the role of students as active contributors and learning partners in school improvement initiatives (Mullis, 2011; Bahou, 2012) and suggests that this participation can become self-sustaining, based upon shared responsibility, and driven by the students themselves (Fielding \& Bragg, 2003; Roberts \& Nash, 2009). It moves towards Fielding's sixth pattern of partnership: Intergenerational learning as lived democracy (2011, pp. 11-13) and emphasises the importance of teachers and students having a physical and metaphorical space (Fielding, 2001b) in which they can learn together and find a shared vision, "a group effort to develop images of 'the future we want together" (Senge et al., 2012, p. 87) and then act on them together.

The focus of the study was an extended student agency model, identified as a Student Learning Community (SLC), and defined as a student-led group focused upon improving teaching and learning within the school. The SLC sought to provide conditions for students to engage in dialogue with each other concerning their learning, and to invite teachers into this space to do the same. It was driven by a need to find a meaningful way to put students at the centre of school improvement initiatives by providing opportunities to speak, not with "exam-accepted voices" (Fielding, 2001a, p.102), but with their own voice: "to foster student voice as a transformative force rather than as an unwitting adjunct to the increasingly irrelevant and pernicious paradigm of school effectiveness" (Fielding, 2001b, p.133). As such, the SLC recognises that effective organisational change can only occur when all actors are able to see how parts of the system affect each other, and in this systems thinking "only the student sees the entire system all the way through" (Senge et al., 2012, p. 125).

As dialogue was the central mechanism of this model, work surrounding cogenerative dialogue and dialogic interactions within an education setting was pertinent to its development. Beltramo's (2018) study in a US school showed that cogenerative dialogue can lead to mutual accountability of school improvement between teachers and students and enable space for teacher agency that supports classroom and professional learning. Mercer and Dawes (2008) emphasised the value of dialogic interaction in schools, which was later explained as "an evolving pedagogical approach in which teachers and learners are actively commenting and building on each other's ideas and reasoning collaboratively" (Hennessy, Mercer \& Warwick, 2011, p. 1910). The work of Beech, Macintosh and MacLean (2010) on generative dialogic encounters between academics and practitioners reinforced its value in knowledge co-production that creates a foundation for further constructive activities. They define dialogic encounters as "engagement between two or more people that goes beyond the trivial, which changes some meanings or processes and/or creates some new knowledge" (2010, p. 1342) and point to participants from both communities acting as colearners and enquirers and consequently feeling a "strong sense of co-ownership and of coproduction" (2010, p. 1362). Senge et al. emphasise the role of continuous dialogue in building a learning organisation as it enables a collective sensibility where "thoughts, emotions, and resulting actions belong not to one individual but to all of them together" (2012, p. 117).

The value of combining dialogue with a student-centred learning community is reinforced by 
Fielding's (2010) work. He suggests that meaningful dialogue can be achieved through person-centred communities within interpersonal spaces, underpinned by mutual trust, care, autonomy and respect, but with particular awareness of manifestations of power and hierarchy. Hence, the influences of power dynamics (Cook-Sather, 2002; Fielding, 2004) and power differentials must be both acknowledged and negotiated so that all parties feel respected and valued (Swaffield, 2008; Beech et al., 2010).

Although, existing scholarship on student voice and dialogic interaction provides insight into the value of enabling conditions for students to become participants in school improvement, there is less known about the processes and impact of specific student agency models that employ dialogic interactions and exist solely within a school setting.

As such, this paper proposes that the processes and impact of the SLC model, which provides a structured space for teachers and students to engage in dialogue outside of the classroom, can be examined by exploring how it can contribute to the conditions required to build and sustain a learning organisation within a school setting. In order to interrogate the proposal above, this paper addresses two research questions:

RQ1 - What are the perceptions of teachers and students about their involvement in student learning communities?

RQ2 - How can a student learning community (SLC) model contribute to the conditions required for learning organisations to emerge?

\section{Design and Method}

\section{Research Context}

The study was conducted in a secondary academy of approximately 1200 students in Essex, England. The school is located in an area of social deprivation and, according to Ofsted reports, the proportion of disadvantaged pupils and those with Special Educational Needs (SEN) is above the national average with approximately one third of students receiving Free School Meals and/or SEN provision. In recent years, over $60 \%$ of students achieved grades 94 (A*-C equivalent) in English and over $55 \%$ in Maths in final year exams. With a central focus on developing the whole child and giving every student the opportunity to be successful, between $96-98 \%$ of students go on to further education or employment following their final year. The researcher holds a professional role on the school's teaching and learning team and played a central role in developing the SLC, hence potential researcher bias must be acknowledged. The SLC from its outset was aligned with the newly appointed Pedagogy Team - a group of five classroom teachers with an interest and expertise in developing teaching and learning within the school. Hence, an existing distributed leadership structure that encouraged a bottom-up approach provided a fitting platform to involve student leaders as well. Members of the SLC received training over a 6-month period in the lead-up to the study that included co-designing their roles, as well as co-developing and trialling student lessons and a lesson observation framework. The SLC worked with teachers who opted in to the process to support a positive and incremental cultural shift.

From the wider group of students $(n=45)$ and teachers $(n=15)$ who engaged with the SLC, a 
purposive sample of students from Years 7 to $10(n=14)$ and teachers $(n=10)$ were chosen. The teacher sample included a reasonable range of age, gender, and teaching experience, and there was representation of ethnic minority groups $(n=3)$, social deprivation indicators $(n=4)$ and SEN $(n=2)$ in the student sample. This small-scale study was based on representativeness of the concept of student agency rather than representativeness of the school site (Mitra, 2004). This limited the external validity of the findings but as a revelatory case study, presented "an opportunity to observe and analyze a phenomenon previously inaccessible to scientific investigation" (Yin, 2003, p, 42).

\section{Study Design}

The findings in this paper were generated by a multi-phase case study, which focused upon participant perceptions of what happens within two distinct approaches of the SLC model: (1) when a team of three to four students facilitates a student-led lesson with the classroom teacher present and following this, engages in a dialogue session with this teacher (student lesson event); and (2) when a team of three to four students observes a lesson delivered by a teacher and following this, engages in a dialogue session with this teacher (student observation event). The study used an exploratory approach (Yin, 2003); using quantitative and qualitative tools to generate stimulus for later interviews and employing narrative as a tool for collecting data and analysing the results (Counsell, 2013). As the concept of learning and the conditions for building learning organisations is situated in socially constructed meanings (Moloi, 2010), the research was approached from a relativist ontological standpoint, as it dealt with participants' perceptions of learning in the classroom and during the dialogue sessions (Guba \& Lincoln, 1994). The learning organisation perspective sees "school transformation through individual and collective learning" (Moi, 2010, p. 623) and is positioned within the lived experiences and perceptions of its actors. Hence, the research design was informed by an epistemological stance that was constructivist (Guba \& Lincoln, 1994) and interpretivist (Grbich, 2007). This stance sees data as the product of multiple constructed realities, and in the study context, teachers and students as active constructors and interpreters of knowledge (Levin, 2000).

The study employed a mixed methods approach (Tashakkori \& Teddlie, 2010) that prioritised the final qualitative (QUAL) phase, with the concurrent quantitative (quan) and qualitative (qual) parts of a questionnaire collected in one instrument and the use of a sequential subsample of qualitative data using an interview (Onwuegbuzie \& Combs, 2010, p. 415).

The mixed methods approach (see Figure 1) allowed data to be used as visual stimulus for the semi-structured interview (QUAL) phase. Quan data from the rating scale items in the questionnaire (on how often certain topics were discussed and to what extent participants perceived that they were valued during dialogic encounters) were presented in tables and graphs to elucidate trends and patterns. Two word clouds were generated from the qual items in the questionnaire to show the most frequent words used by the teacher and student participant groups. These visual representations, along with still photos taken from the video data of teacher-student positioning during the dialogue sessions, provided a reference point and stimulus for the interviews. In addition, a cursory content analysis of the qual data generated questions for the semi-structured interview that encouraged participants to provide narrative responses specific to their experience of the classroom event, as well as share broader perceptions of the SLC model.

Following the interview (phase 3), a thematic analysis of the QUAL data from the survey and 
interview was conducted using in vivo codes - words or phrases borrowed directly from responses (Evans, 2017, p. 268) - by the researcher and two other education professionals not involved in the study. This supported the internal validity of the study but also enabled a focus on the variables and anomalies in the data, rather than on the generalised findings gleaned from the quantitative analysis. Codes identified across the survey and interview data were compared in order to verify recurrent patterns (ibid.) and qualitative coding was compared to quantitative items to confirm or extend upon the themes generated.

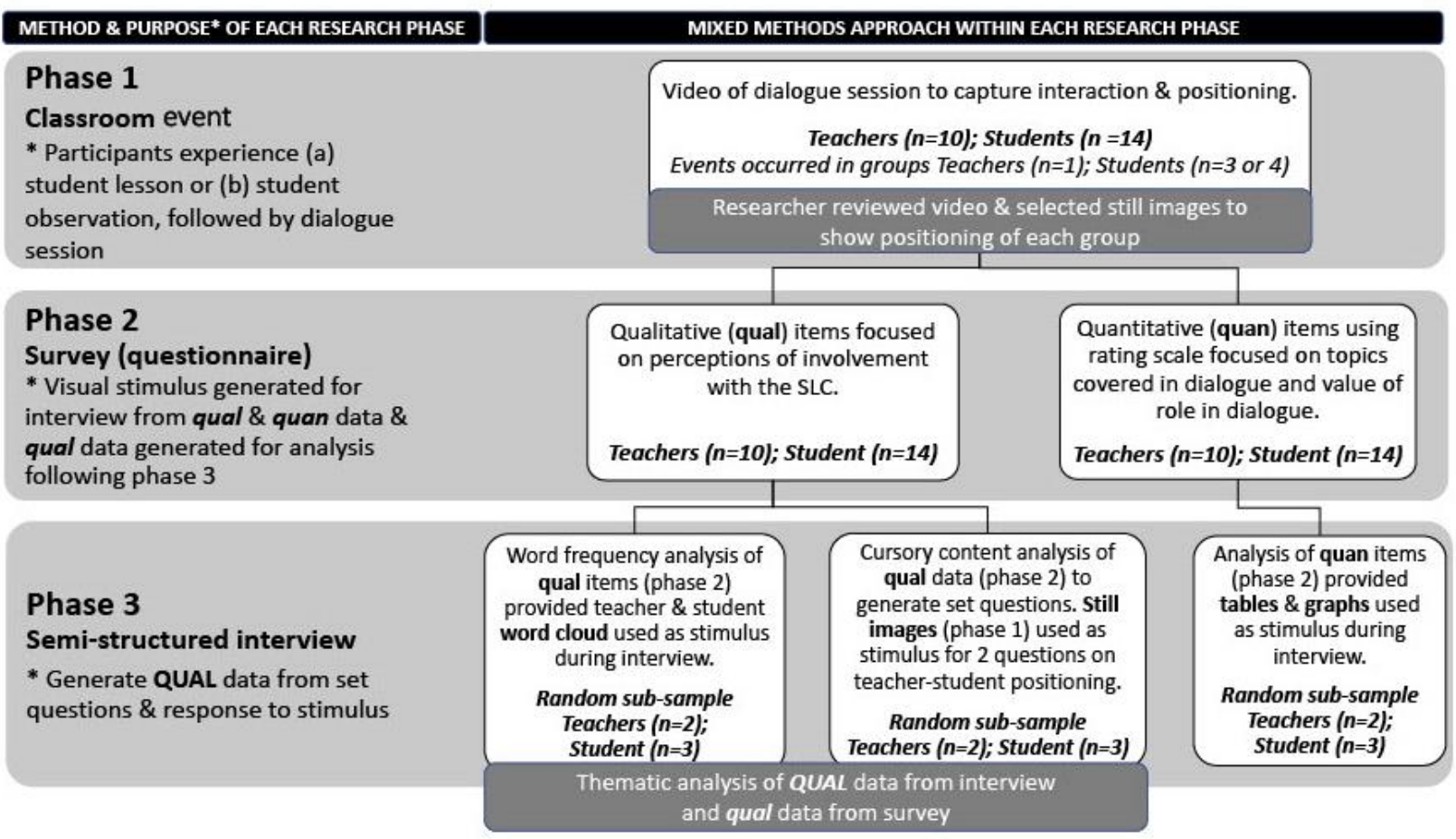

Figure 1-Phases of Research

\section{Ethics}

Informed consent was sought from participants, detailing the use of the video in the interview and anonymised use of survey and interview data. In recognition that the relationships between teacher and student participants may be challenged in the study process (Harcourt \& Einarsdottir, 2011), a support network enabled participants to address any concerns. The researcher maintained a position of reflexivity by engaging regularly with the senior leadership team about how the school's culture could be impacted as a result of the study's findings.

\section{Findings}

The key themes emerging from the data reveal teacher and student perceptions of what happened when the SLC model was introduced in the case study school (RQ1) and the proposed links to Senge's (2006) disciplines for creating the conditions required for a learning organisation (RQ2). The findings for both RQ1 and RQ2 are summarised in Table 1. Key insights from the findings for RQ1 are described below and links to the learning organisation disciplines (RQ2) are discussed in the final section. Participants have been 
allocated pseudonyms for ease of identification and to ensure anonymity, with teachers identified using titles and surnames and student identified using first names. Their responses come from both the survey and interview data.

\begin{tabular}{|c|c|}
\hline & Summary \\
\hline
\end{tabular}

discipline

1. Honest and authentic awareness of what works
Students demonstrated an honest and pragmatic awareness of what works in the classroom. It was also found that the depth of insight that occurs when teachers and students discuss shared experiences of teaching and learning can reveal assumptions and perceptions and lead to reflection of personal capacities.
Mental Models

In many instances physical positioning in the dialogue sessions, as well as
2. The role of teamwork in softening the power hierarchy traditional beliefs about the practice of teaching, still supported a culture where the teacher was seen as the authority figure. However, by providing a space for team learning to develop between teachers and students, the power hierarchy was disrupted and at times softened significantly.

Team Learning

Personal Mastery

Mental Models

\section{The shared ownership of school transformation}

The involvement of SLCs in lessons and in dialogic encounters, on several occasions, led to a sense of shared responsibility for school improvement. Also, it was found that negotiating disagreement and difference during dialogue was imperative in the co-creation of an organisation.
Shared Vision

Mental Models

\section{An alternative to traditional accountability measures}

The SLC model can be seen as an alternative means through which teachers, and schools, could be made accountable to the expectations of teaching and learning in ways that encourage collaborative growth that is invited not enforced. If the dangers of manipulating student agency are resolved, the SLC model could create more meaningful ways to see and respond to the complexity of the school organisation.
Systems Thinking

Team Learning

Table 1 - Key themes emerging from case study

\section{Honest and Authentic Awareness of What Works}

Student contributions during dialogue sessions were reasonable and realistic. As Mrs. Kay reflected, students "avoided saying things like 'sit with friends'...they were honest about what happens, they were aware of what happens", and Mr. Smith commented, "I didn't know how aware they were of what they liked... [their ideas] were not idealistic but realistic". They were honest and pragmatic and their ideas were often accompanied by mature reasoning and tangible teaching strategies: "expanding solo taxonomy into different subjects and making sure that different learning styles are used throughout all subjects so that everyone has a chance to learn" (Tom). As Sarah explained, during the dialogue they discussed "the importance of interesting starters to engage students in learning before the lessons begin as well as the importance of plenaries, so that students recognise what they have learnt". In some cases, teachers indicated that they had made changes to their practice based upon feedback from the lesson observation: "I have already changed my seating plans as a result" (Miss Clark).

It was found that there was value for teachers in students demonstrating their ideas through 
student lessons: "the students used SOLO to plan/deliver the main activity of the lesson. I have never used this in my teaching before, but I will certainly give it a try" (Mr. Saye). Several teachers indicated a desire to observe students demonstrating their ideas in the future, as this enabled them to see them in practice, and evaluate the reaction and progress of the class. Mrs. Kay noted that students often made "rookie mistakes" in their lessons but they were still happy to pursue ideas and strategies that they believed would improve learning. In the student lesson events, students showed a willingness to try new strategies and ideas even though they risked making mistakes, which could encourage teachers to do the same: "...we were able to show and share our teaching ideas with staff even if they were different" (Daniel).

Evidently, students within the SLC viewed themselves as agents of change because of their ability to contribute new pedagogical ideas, yet they also identified that they were on a learning journey with teachers. As Robert concluded "now that (teachers) have embraced technology, they are able to come up with ideas that are more inclusive...it is important that they are coming from teachers as well". These thought-provoking exchanges provide an area of shared experience as the focus for discussion, enabling teachers and students to move beyond a superficial feedback session and forge a new understanding of how to move forward in the best interests of everyone in the school.

\section{The Role of Teamwork in Softening the Power Hierarchy}

Analysis revealed that traditional power structures that relegated students to the role of receivers and responders rather than agents still existed in the case study school. As Mr. Flynn observed when identifying the word 'ask' in the student word cloud, the "student role is asking the teacher a certain amount...student questions and teacher answers". The dominant belief is that teachers hold the position of authority in school. For some teachers this was evident in their recognition of the difficulty in assuming a different role: "I found it quite unusual and difficult at first to let go of control from my usual capacity in the room" (Miss Spark). For other teachers, it was awareness of the power dynamics during the dialogue session: "it may have been that they were intimidated by my presence and position, and felt too uncomfortable to really criticise my lessons" (Mr. Smith).

Some students also recognised the unfamiliarity of fulfilling a different role. As Sophie described, "it was strange at first sitting in a classroom and not following the teacher's instructions and doing the work set". When asked in the quan section of the survey "whether they felt they were able to offer suggestions without fear that contributions would be seen as irrelevant or silly', 29 per cent of students indicated unsure, whilst all teachers indicated that they agreed or strongly agreed. Although this is a modest percentage in a small sample, it did justify further exploration in the interviews. When asked why this could be, Robert suggested that fear is there because "they are the people teaching...students are scared to talk to the teachers, worried about how teachers might react. [Students] like to sound smart but have to use the words they have and teachers can choose if they take students' comments on board". This could suggest that students felt it was necessary to use a predefined language for their comments to be deemed valuable. Thus contributing to feelings of insecurity and difficulties surrounding the inclusion of marginalised student voices (Black, 2011).

In her interview, Samantha suggested that students' fear of contributing could be a result of the culture that was created and supported by some teachers: "some teachers do have 
negative views...that students shouldn't have the power. But it is their own lack of selfconfidence and unwillingness to embrace new opportunities". This was supported by Tom's assertion that teachers can be "quite one-sided, quite a fixed mindset...teaching the same for years and might not want to change it". The existence of traditional power distinctions was also identified through participant interpretations of the photos of the dialogue sessions, with several noting the oppositional nature of teachers who were sitting directly across from students or at the head of the table. As Hannah commented, "you can't expect laid-back students to have a conversation with teachers [like that]...teachers should be happy to sit beside students".

Instinctively though, teachers may have felt the need to guide students in an environment where the conditions were largely unknown: "I took the driver's seat and ended up questioning [students]" (Mr. Smith). On the other hand, some students showed the capacity to renegotiate these traditional structures; as Mrs. Kay commented, "I didn't know what to expect, but [the students] owned the space as they were there before me". This does point to the possibility of softening the hierarchy through careful attention to the creation of dialogic spaces that promote equality and dissolve traditional authority roles. Both teachers and students offered suggestions for creating these spaces. Miss Clark described, "it might help to sit around small, round tables...perhaps meeting, getting food together and walking to the [table]" and Daniel also suggested round tables as they enable "everyone [to get] their opinion across".

\section{The Shared Ownership of School Transformation}

Most student participants expressed awareness that their involvement in the SLC can have value and be meaningful in developing their school. As Beth described "I have learnt (that) as students we make a valuable contribution to the teaching and learning environment". And Samantha gave a specific example of where she saw the impact of her advice: "the teacher said he would use our idea more and he has. Before he never used iPads, now we are using Kahoot. There has been a difference". In many cases, the SLC enabled students to see when their input was being acted upon and this led to a sense of ownership in the changes that were occurring in their school.

Interestingly, students viewed their role in school improvement as stretching beyond the events of the study. As Daniel concluded, "I now know how classes are improved and it lets me talk to my own teachers about improving their own classes". Similarly, Cassie saw the study as an opportunity to learn in order to contribute further: "this has been valuable for improving my learning as I am able to analyse lessons better and help to improve the teaching within the school".

One of the most valuable findings of the study was the awareness by some participants that mutual learning comes as much from difference as from consensus. As Samantha described, "[the teachers] listened... some ideas they didn't agree with, there were things that they questioned, but that was good as it helped us as well". This is reinforced in Robert's assertion: "I didn't see it as disagreements, more like taking other people's ideas and discussing them". And as Mr. Grange noted, each person in the dialogue session "offered a different dimension to the conversation where differing ideas highlighted an alternative approach to a topic". 


\section{An Alternative to Traditional Accountability Measures}

Generally, participants wanted to see the model continue as a cyclical process of selfimprovement: "I would like to have the [SLC] involved at the planning stage, then we could plan together; I deliver, we evaluate the strategy and the delivery of the strategy and 'replan' as a result" (Mr. Watson). This was reinforced by Beth's comment that "it could be improved by another observation later to see whether the plans have been put in place". The events driven by the SLC were seen as a joint means through which a lesson could be discussed and improvement could occur collaboratively. Miss Spark suggested that student observation (followed by a dialogue session) enabled authentic and meaningful feedback on learning that did not compromise the integrity of her role as a teacher:

...students (in class) act differently with teacher observers, but not with student observers... for them, they see a lesson just like normal. It is more of a true reflection as I wasn't as nervous... whenever I'm observed I get very anxious... (but with student observers) it was massively different, a lot less intimidating... they realise that you're not a performing monkey... they understand.

This strengthens the possibility of these events being valuable in school improvement, as they enable a dynamic in which teachers feel at ease and more genuine insight into everyday classroom practice can occur. The model also provided opportunities for quality teaching and learning to be recognised: "they were very complimentary...it was nice to have positive feedback" (Mrs. Kay).

\section{Discussion and Conclusions}

The study sought to investigate the perceptions of those involved in a student learning community model, which saw the SLC lead the planning and facilitation of a lesson, or observe a teacher-led lesson, followed by engagement in dialogue with the teacher (RQ1). It found that teachers and students perceived their involvement in the SLC as enabling a space where authentic and relevant teaching and learning ideas could be discussed in a manner where both students and teachers could renegotiate their roles and develop confidence in contributing to their school. Teachers, and particularly students, saw the value of engaging in dialogue around learning, even if this meant discussing differing perspectives, and it was these exchanges that could provide a more effective framework for developing teaching and learning practices within schools.

The section below draws upon the key findings described above to explore the value of a SLC model in contributing to the conditions required for learning organisations to emerge (RQ2).

Some criticism of student agency initiatives (and indeed the reluctance of teachers within this school) has come from confusion around the role of the child in school (Thompson, 2009; Rudduck \& Fielding, 2006) and scepticism about whether students can contribute to teaching practice with any level of expertise and criticality (Black, 2011). Yet it emerged from the research that students do not need to be experts in content to contribute to school improvement, instead they enable teachers to also see themselves as learners, a fundamental condition to improving teaching practice (Senge et al., 2012; Hargreaves \& Fullan, 2012). Indeed, involvement with the SLC could provide the conditions for teachers to consider their mental models. As Argyris explains, "changing private assumptions involves helping people to become aware of these internal maps, helping them see how their present 
assumptions are counterproductive for the very kind of learning they need to be effective" (1977, p. 120).

In some cases, teachers indicated that they had made changes to their practice based upon feedback from the lesson observation: "I have already changed my seating plans as a result" (Miss Clark). These findings are supported by Pedder and Mclntyre's study, which concluded that students had an authentic grasp of what works for them, and what teachers could do to enable these conditions: "their accounts expressed a wealth of contextualised, concrete practical ideas as a potential resource for informing teachers' planning and practice" (2006, p.149). Crucially, dialogic encounters can enable a culture of partnership where students communicate ideas that work for them, and consequently provide teachers with actionable suggestions for pedagogy. However, students' acknowledgment of the fear surrounding their contributions acts as a cautionary note that dialogic encounters may reinforce the power hierarchy and lead to manipulation of student involvement. As Fielding (2001a) examined in his study, the existence of a power hierarchy can lead one person to dominate the space during dialogue and can threaten the emergence of democratic dialogic communities.

Both teachers and students emphasised the value of discussing differing opinions and diverse ideas. Certainly, it emerged that it is possible for diverse perspectives to contribute to a shared transformative agenda (Beech et al., 2010). As Fielding explains, "even if they identify similar issues as being of particular importance, invariably they will have different understandings of their nature and significance" and "in those differences lie the possibilities of creativity and renewal" (2004, p.307). In fact, these differences are key to understanding individual mental models and examining assumptions, and seeing an organisation from all perspectives is essential in building a learning organisation as "no one person's perspective is likely to be complete" (Senge et al., 2012, p. 126). It is worth noting here that although teacher nominations were used to encourage a diversity of students, the SLC is a voluntary student team and cannot purport to be representative of all marginalised groups. Thus, further studies and practices need to ensure that marginalised students (who are traditionally less likely to involve themselves in these initiatives) are mobilised to participate (Mullis, 2011), and to create a space where "diversity and difference are seen as the very conditions for engagement in the first place" (Cook-Sather, Bovill \& Felton, 2014, p. 208).

What was particularly enlightening in the findings was that in offering suggestions for improving the dialogic space, participants identified factors that aimed to flatten the traditional hierarchy inherent in the teacher-student relationship: equal participation for all involved, acknowledgement of different ideas and using a neutral space and a round table. In addition, students tended to write and speak using collegial terms - often using us and we: "we need to work hard to improve our lessons so we can overall make a difference" (Tyler). In a similar light, Mr. Knott indicated that creating a culture where teachers supported students in offering suggestions to teachers was not only possible, but essential: "[students] are very used to being told that they are not right by the teacher...them knowing that they are allowed to talk about teaching...told the value of their contribution, would help this". As Rudduck and McIntyre note, teacher-student dialogue can be "a way of showing trust and respect for pupils and of winning their trust" (2007, p. 179). This reinforces Senge's (2006) discipline of personal mastery, which holds that learning organisations should create a set of practices to enable all individuals to develop a personal vision that feeds into a collective commitment to discuss those potential realities. 
Furthermore, students' reflections on their participation in the student lessons showed that the SLC was part of a much larger team of students who were willing to accept new dynamics and support their peers as agents within the school: "the classes respected the group as if we were real teachers and listened to us and cooperated with us..." (May). It was not just about the SLC being a catalyst for changing the traditional power structure by fulfilling non-traditional roles, it was about their involvement legitimising a culture where all students and teachers can work alongside each other as partners in learning and school improvement. This is not to ignore the crucial role of teachers as those with the experience and knowledge to make curriculum choices, maintain a safe classroom environment, and oversee the well-being of students. Rather, the SLC model offers learning through listening and watching, as well as supporting. It does not assume that the learning will be acted upon, instead it provides possibilities for reflection and a willingness to break away from traditions and old assumptions and enter into interactions of mutual learning and negotiation (Pedder \& McIntyre, 2006).

The student lesson event and most significantly, the student observation event, offered a way in which a lesson could be discussed and improvement could occur collaboratively and continually. This is distinctly different to traditional accountability measures, such as observations from external or internal observers, where teachers are judged using performativity frameworks (Ball, 2003) and often left isolated after the feedback process. It emerged from teacher and student perceptions that in many ways, accountability measures in schools have forgotten the power of positive feedback for teachers and, in privileging a deficit model that focuses on what is not being done, these measures have drowned out the effective practice that is occurring. As such, a SLC model could provide a means for improvement that is both discursive and constructive, whilst also recognising what is already great. Additionally, by providing the space for the co-construction of meaning, dialogic encounters promote systems thinking by creating awareness of "how individuals affect others in the system and [encouraging a re-examination of] the assumptions that underlie practices" (Moloi, 2010, p. 628), and in doing so, enable accountability measures that are more meaningful than traditional measures of performativity.

It was evident that the dialogic encounters created a collegial transparency and sensitivity that welcomed different perspectives and by encouraging the team learning of skills and practices, "set the tone and establish[ed] a standard for learning together for the larger organization" (Senge et al., 2010, p. 219). As such, the SLC offered a symbiotic space for teachers and students to engage in team learning (Senge, 2006) and provided valuable insight into negotiating the traditional hierarchy in school that has often become a barrier for developing as a learning organisation. If teams learn, they become a "microcosm for learning" (Senge, 2006, p. 219) throughout the school and a new norm emerges where "teachers follow as well as lead, and students lead as well as follow" (Cook- Sather, 2006, p.345).

The findings also showed that students recognised that their experiences had enabled them to learn and develop as more critical agents within their school. This is supported by Thompson, who found that when directly involved in "the organisation of their learning, [students] are likely to learn more effectively"(2009, p. 685) and Waters, who notes that students who are consulted become "more responsible citizens, more confident individuals and more successful learners" (2011, p. 207). In expressing a desire to continue in these endeavours, students revealed that they felt a sense of ownership, not only in their own 
learning journey, but also in pedagogical improvement across the school. Here, we can see team learning in the form of a "regular willingness, as a recurring group of people, to think and act together as a living system" (Senge et al.2012, p. 115). Markedly, this was a smallscale study over a short period of time and there is limited evidence from longitudinal studies on student agency initiatives. Hence it is difficult to ascertain whether this could lead to sustained action and systemic change.

Nevertheless, it became evident that the dialogic encounters led teachers and students to develop a sense of shared responsibility in the improvement of their school, as Mr. Grange reflected,

Listening to the student perspective on their educational experience is often ignored and incorporating feedback from their experience of various teaching and learning strategies/approaches can only advance our pedagogical knowledge and increase student attainment by offering them a more inclusive learning environment that they can take part ownership of.

Similarly, Fielding found that dialogue supported "the transformative notion of education at the heart of which lies the commitment to teaching and learning as a genuinely shared responsibility" (2001a, p.137). This view is reinforced by Mullis (2011), who notes the sense of accountability felt by student learning partners following their dialogue with teachers and their recognition that sustained change requires the development of mutual trust and a shared understanding between students and teachers. As Moloi describes, dialogue enables the creation of a "sense of purpose that binds people together and propels them to fulfil their deepest aspirations" (2010, p. 628). It creates a shared vision for the organisation that places everyone in a "creative orientation, where every individual makes choices about their desired future" (Senge et al., 2012, p. 94).

Overall, there is evidence to suggest that student agency models can play a significant role in building schools as learning organisations. In exploring learning communities through student involvement, the study also raised questions concerning how we think about teacher learning communities, namely the value of training for effective dialogue, the importance of physical and metaphorical space, and the ways in which learning communities can counter damaging performativity frameworks. Moreover, the study points to the need for educators to engage in a wider conversation about schools as learning organisations and to acknowledge, as Hargreaves and Fullan comment, that school improvement, and whole system change "requires individual and collective acts of investment in an inspirational vision and a coherent set of actions that builds everyone's capability and keep everyone learning as they continue to move forward" (2012, p. xvii). The findings in this paper suggest that a structured student agency model could enable this to occur on broader and more meaningful scale by supporting the disciplines that underpin a learning organisation.

This paper offers some recommendations concerning the implementation of a student learning community as a continual, integrated model within schools. Notably, previous inquiry has warned of initiatives such as these leading to tokenism where the initial novelty of student involvement and dialogic encounters bolsters unrealistic expectations and manipulation from school leaders, and later leads to "the unwitting corrosion of integrity....betrayal of hope, resigned exhaustion" (Fielding, 2004, p.296). Hence, more rigorous research is needed to interrogate how we navigate the power differential in teacher-student relationships and to ascertain whether models such as this can be sustained 
over time and in other school settings. That is, whether student agency models can incorporate adequate training and support for students and teachers, whilst nurturing the intuition, honesty and authenticity that can make student agency transformational within schools. As well as assessing whether structured dialogue, which is central to these models, has a shared purpose, generates sustained mutual respect between teachers and students, and reduces the marginalisation of certain students. Lastly, in recognition of the limitations of self-report, there is a need for further investigation that looks beneath the perceptions of teachers and students and focuses upon the processes and mechanisms of these models. These limitations will be addressed in further research through a series of case studies that employ a theory-building process-tracing methodology (Beach \& Pederson, 2013; Vennesson, 2008).

It is hoped that with the insights and recommendations gleaned from continual research into this field, student involvement and dialogic encounters become the means through which we can truly challenge the damaging forces in current education agendas, embrace the uncertainty of learning and imaginatively collaborate to find better ways of moving forward together.

"To live with ambiguity, to challenge certainty, to creatively encounter, is to arrive, eventually, at 'seeing' anew' (Simons, 1996, p.238). 


\section{References}

Argyris, C. (1991). Teaching smart people how to learn. Harvard Business Review, 4(2), 4-15.

Argyris, C. (1977). Double loop learning in organisation. Harvard Business Review, 55(5), 115125.

Bahou, L. (2012). Cultivating student agency and teachers as learners in one Lebanese school. Educational Action Research, 20(2), 233-250.

Ball, S.J. (2003). The teacher's soul and the terrors of performativity. Journal of Education Policy, 18:2, 215-228.

Beach, D. \& Pederson, R.B. (2013). Process Tracing Methods: Foundations and Guidelines. Michigan: University of Michigan Press.

Beech, N., Maclntosh, R., \& MacLean, D. (2010). Dialogues between Academics and Practitioners: The Role of Generative Dialogic Encounters. Organization Studies, 31 (9\&10), 1341-1367.

Beltramo, J.L. (2018), Developing Mutual Accountability between Teachers and Students through Participation in Cogenerative Dialogues. International Journal of Student Voice, 3 (1). https://ijsv.psu.edu/?article=developing-mutual-accountability-between-teachers-andstudents-through-participation-in-cogenerative-dialogues

Black, R. (2011). Student participation and disadvantage: limitations in policy and practice, Journal of Youth Studies, 14(4), 463-474.

Czerniawski, G., \& Kidd, W. (2011) The student voice handbook: bridging the academic/practitioner divide. Bingley: Emerald.

Cook-Sather, A. (2006). 'Change based on what students say': preparing teachers for a paradoxical model of leadership, International Journal of Leadership in Education: Theory and Practice, Vol. 9 No. 4, 345-358.

Cook-Sather, A. (2002). Authorizing Students' Perspectives: Toward Trust, Dialogue, and Change in Education. Educational Researcher, 31(4), 3-14.

Cook-Sather, A., Bovill, C., \& Felten, P. (2014). Engaging Students as Partners in Learning and Teaching. San Francisco: Jossey-Bass.

Counsell, C. (2017). Interpretivism: meeting our selves in research. In E. Wilson (Ed.), Schoolbased Research: a guide for education students. London: Sage Publications Ltd., 341-368.

Evans, M. (2017). Analysing Qualitative Data. In E. Wilson (Ed.), School-based Research: a guide for education students. London: Sage Publications Ltd, 260-273.

Fielding, M. (2011). Student Voice and the Possibility of Radical Democratic Education: ReNarrating Forgotten Histories, Developing Alternative Futures. In G. Czerniawski \& W. Kidd 
(Eds.), The student voice handbook: bridging the academic/practitioner divide (pp. 3-17). Bingley: Emerald.

Fielding, M. (2010). The radical potential of student voice: Creating spaces for restless encounters. The International Journal of Emotional Education, 2(1), 61- 73.

Fielding, M. (2004). Transformative approaches to student voice: theoretical underpinnings, recalcitrant realities. British Educational Research Journal, 30(2), 295-311.

Fielding, M. (2001a). Beyond the Rhetoric of Student Voice: new departures or new constraints in the transformation of 21st century schooling?. Forum, 43(2), 100-110.

Fielding, M. (2001b). Students as Radical Agents of Change. Journal of Educational Change, 2(2), 123-141.

Fullan, M. (2013). The New Pedagogy: Students and Teachers as Learning Partners. LEARNing Landscapes, 6(2), 23-29.

Fielding, M., \& Bragg, S. (2003). Students as researchers: Making a difference. Cambridge: Pearson Publishing.

Garvin, D. A., Edmondson, A. C., \& Gino, F. (2008). Is yours a learning organization?. Harvard Business Review, 86(3), 109-119.

Giles, C. \& Hargreaves, A. (2006). The Sustainability of Innovative Schools as Learning Organisations and Professional Learning Communities During Standardized Reform. Educational Administration Quarterly, 42(1), 124-156.

Grbich, C. (2007). Qualitative Data Analysis: an introduction. London: Sage Publications Ltd.

Guba, E.G. \& Lincoln, Y.S. (1994). Competing Paradigms in Qualitative Research, in Denzin, N. K. \& Lincoln, Y. S. (Eds.). Handbook of qualitative research. Thousand Oaks, CA: Sage Publications, 105-117.

Harcourt, D. \& Einarsdottir, J., 2011. Introducing children's perspectives and participation in research. European Early Childhood Education Research Journal, 19(3), 301-307.

Hargreaves, A. \& Fullan, M. (2012). Professional capital: Transforming teaching in every school. New York: Teachers College Press.

Hargreaves, A. \& O'Connor, M. (2018). Collaborative Professionalism: When Teaching Together Means Learning for All, Thousand Islands, California: Corwin Press.

Hargreaves, D.H. (2010). Creating a self-improving school system. Nottingham: National College for School Leadership.

Hart, R. (1992). Children's Participation: From Tokenism to Citizenship. Florence: UNICEF International Child Development Centre.

Hennessy, S., Mercer, N., \& Warwick, P. (2011). A Dialogic Inquiry Approach to Working with Teachers in Developing Classroom Dialogue. Teachers College Record, 113(9), 1906-1959. 
Hill, S. (2015). Flattening the hierarchy: the role of student agency in school improvement. (Unpublished master's thesis). University of Cambridge, Cambridge, UK.

Levin, B. (2000). Putting Students at the Centre of Education Reform. Journal of Educational Change, 1(2), 155-172.

Lundy, L. (2007). 'Voice' is not enough: conceptualising Article 12 of the United Nations Convention on the Rights of the Child, British Educational Research Journal, 33(6), 927-942.

Mercer, N., \& Dawes, L. (2008). The value of exploratory talk. In Mercer, N. \& Hodgkinson, S., Exploring talk in school. London: SAGE Publications, 55-71.

Mitra, D.L. (2004). "The Significance of Students: Can Increasing "Student Voice" in Schools Lead to Gains in Youth Development?", Teachers College Record, 106(4), 651-688.

Moloi, K.C. (2010). How can schools build learning organisations in difficult education contexts?. South African Journal of Education, 30(4), 621-633.

Morgan, B. (2011) Consulting pupils about classroom teaching and learning: policy, practice and response in one school, Research Papers in Education, 26(4), 445-467.

Mullis, G. (2011). Student Voice: Changing Practice and Developing Partnerships. In G. Czerniawski \& W. Kidd. The student voice handbook: bridging the academic/practitioner divide (pp. 209-224). Bingley: Emerald.

Onwuegbuzie, A. \& Combs, J. (2010). Emergent data analysis techniques in mixed methods research: a synthesis. In Tashakkori, A., \& Teddlie, C. (Eds.), SAGE handbook of mixed methods in social \& behavioral research (pp. 397-430). Thousand Oaks, CA: SAGE Publications, Inc.

Pedder, P. \& McIntyre, D. (2006). Pupil consultation: the importance of social capital. Educational Review, 58(2), 145-157.

Pedler, M. \& Burgoyne, J.G. (2017). Is the learning organisation still alive?. The Learning Organisation, 24(2), 119-125.

Reynolds, T., Murrill, L.D. \& Whitt, G.L. (2006). Learning from Organisations: Mobilising and Sustaining Teacher Change. The Educational Forum, 70(2), 123-133.

Roberts, A. \& Nash, J., (2009). Enabling students to participate in school improvement through a Students as Researchers programme. Improving Schools, 12 (2), 174-187.

Rudduck, J. \& Fielding, M. (2006). Student voice and the perils of popularity. Educational Review, 58(2), 219-231.

Rudduck, J., \& McIntyre, D. (2007). Improving learning through consulting pupils. London: Routledge.

Senge, P. M. (2006). The Fifth Discipline: the art and practice of the learning organisation, London: Random House. 
Senge, P., Cambron-McCabe, N., Lucas, T., Smith, B., Dutton, J., \& Kleiner, A. (2012). Schools That Learn. London: Nicholas Brealey Publishing.

Shier, H. (2001) Pathways to Participation: Openings, Opportunities and Obligations. Children \& Society, 15, 107-117.

Simons, H. (1996). The Paradox of Case Study. Cambridge Journal of Education, 26(2), 225240.

Stoll, L. \& Fink, D. (1996). Changing Our Schools: Linking School Effectiveness and School Improvement. Buckingham: Open University Press.

Sun, H. (2003). Conceptual clarifications for 'organisational learning', 'learning organization' and 'a learning organization'. Human Resource Development International, 6(2), 153-166.

Swaffield, S. (2008). Critical friendship, dialogue and learning, in the context of Leadership for Learning. School Leadership \& Management: Formerly School Organisation, 28(4), 323336.

Tashakkori, A., \& Teddlie, C. (2010). SAGE handbook of mixed methods in social \& behavioral research: second edition, Thousand Oaks, CA: Sage Publications Inc.

Thomas, K. \& Allen, S. (2006). The learning organisation: a meta-analysis of themes in literature. The Learning Organisation, 13(2), 123-139.

Thompson, P. (2009). Consulting secondary school pupils about their learning. Oxford Review of Education, 35(6), 671-687.

Vennesson, P. (2008). Case Studies and process tracing: theories and practices. In D. Della Porta \& M. Keating (Eds.), Approaches and Methodologies in the Social Sciences: a pluralist perspective. Cambridge: Cambridge University Press, 223-239.

Vince, R. (2018) The learning organization as paradox. The Learning Organisation, 25(4), 273280.

Waters, M. (2011). Setting the Learning Agenda: Can Pupils Do That?. In G. Czerniawski, \& W. Kidd (Eds.), The student voice handbook: bridging the academic/practitioner divide (pp. 199207). Bingley: Emerald.

Yin, R.K. (2003). Case study research: Design and methods. London: Sage publications. 